9. B. Rampton. Language Crossing and the Problematisation of Ethnicity and Socialisation. Pragmatics. № 5 (4) (1195). pp. 485-513.

10. J. N. Jørgensen. Polylanguaging in Superdiversity. Polylanguaging in Superdiversity. Diversities. № 13 (2) (2011), pp. 23-37.

11. J. Blommaert. Language and superdiversity. Diversities. № 3 (2) (2001). pp. 1-21.

12. A. Pennycook. Digital Metroliteracies: Space, Diversity and Identity. Handbook of Writing, Literacies, and Education in Digital Cultures. Routledge, London (2018). pp. 211-223.

DOI 10.15826/B978-5-7996-3081-2.24

\title{
Boundaries of Multimodality in Virtual Information Environment Design
}

\author{
Kalaykova Julia', Pankina Marina² \\ 1 Ural State University of Architecture and Art / Ural Federal University, \\ Ekaterinburg, Russia \\ 2 Ural Federal University, Ekaterinburg, Russia \\ Corresponding author: Pankina Marina, marina.pankina123@gmail.com
}

Abstract. Generating meanings through the use of various modes, simultaneous holistic multi-modal texts form the cognitive canvas of a virtual information environment. With reference to the current scientific discourse, we explore insights into the identification and interpretation of meanings in their multiplicity as a characteristic feature of objects of virtual information environment design and raise the question of human limits and potentialities in the perception of communicative images and the issue of communication in the virtual environment as a goal of design.

Keywords: multimodality, environment design, virtual information

\section{Introduction}

The growing computerization and virtualization of the information environment, particularly in the context of massive forced changeover to online 
formats in industry, commerce and education in the spring of 2020, are opening up new communication realities and set out new requirements concerning information management and contents. The purpose of this paper is to define boundaries of multi-modality in virtual information environment design. In the context of this study, boundaries are understood, on the one hand, as limits to the multiplicity of meanings, text superpositions, and to the amount, connection and bundling of information; on the other hand, as limits and constraints related to the physical and psychological capabilities of human perception; on yet another hand, moral principles, norms and rules constituting the designer's professional ethics.

The paper reviews current studies and views of various authors on multi-modality in design, and describes the properties of the simultaneousness and holisticity of multimodal design-texts with reference to the socio-cultural context in which designers use a lot of citations and metaphors. The issue of the designer's freedom is raised within the framework of discourse theory regarding the limits to which the potential of multimodal design-texts could be used in professional activities. The apriority of multimodal perception and the conventionality of multimodal design-texts are considered as tools for achieving design communication objectives.

\section{Methodology and methods}

The theoretical framework of the study is provided by books, articles and monographs from the areas of art and cultural studies, philosophy, social semiotics, discourse theory and theory of design devoted to trends in the development of multi-model texts in the virtual information environment.

The leading role in the study belongs to the systems approach and the social semiotic methodology, oriented towards identifying resources for constructing communication situations in social and cultural circumstances and defining meaning-making through the social dimension. The work is based on an integrative communicative-activity approach in which design is considered through the lens of how effective the impact on the user is.

Multi-modal objects of design are considered as a system, as a whole complex of interrelated participants, interactive processes and elements: the customer, the designer (programmers and other related professionals), the virtual information environment, and the user. Within the framework of communicative, discursive and functional-stylistic approaches, design operates as text, context, and discourse. A multi-modal design-text exists 
as a unit of meaning in a certain context that finds expression in discourse ensuring a direct experience of sign-epistemic activity. Design discourse sets contextual coordinates: linguistic, situational, and cultural. Being based on previous sign experience, discourse represents design of a future experience employing directly experienced sign communication.

The study takes advantage of the methods of observation, idealization, analogy, generalization, analytico-synthetic method, and abstraction techniques.

\section{Description of the study}

Design has been historically considered as an activity to create esthetically expressive and functional objects. This type of visual creativity produced graphic designs implemented in printed, i. e. analogue form (posters, advertisements, labels, magazines, TV commercials, etc.) as embodiments of multimodality. Design is a multimodal "text-making" activity since it always involves work with texts, contexts and meanings. Even in the fabric of an object of industrial design "serving to give the 'design-text' a metaphoric coloring" one can see "text-making" [Lavrentyeva, 2008, 11]. Thus, we consider products of design as texts in the postmodernist paradigm of the world outlook.

3.1. Multimodal design-text. A review of studies

Design uses the expressive means of art and, thus, may be identified to a certain extent with fine art (Rozenblum, 1974). In spite of the increasing potentialities of the socio-semiotic toolkit in the interpretation of works of art (including fine arts), there are few studies into multimodality in design, and these have been mostly carried out in English-language communication research.

The available studies of multimodality in design may be conventionally divided into two directions: the first considers design as text within the framework of semiotics of culture (Chernevich, 1975; Lavrentyeva, 2008; Zherdev, 2010); the second treats design as discourse in which the addressee (user) is an active image-producing subject while the creolized product of design (the fabric of which consists of two inhomogeneous parts: verbal (text) and non-verbal (illustrations, photographs, graphics, etc.)) possess the property of persuasiveness (the author of the message exerts influence on the addressee with the purpose of convincing him/her of it) (Kress \& Van Leeuwen, 2006; Hansen \& Machin, 2013; Yassine, 2014; Ledin \& Machin, 2016).

Researchers pertaining to the second direction use the theory and methodology of social semiotics and the toolkit of multimodal discourse analy- 
sis, combining discourse analysis procedures with extralinguistic elements of the message included in the scope of attention. Some authors consider the multimodality of design products allowing for the socio-political context (critical multimodal discourse analysis); in this concept, multimodal design-texts act as a powerful tool of social influence and the designer, thus, possesses power.

Considering multimodality in design, mention should be made of the work by Kress and Van Leeuwen "Reading Images: The Grammar of Visual Design", which examines multimodal design-texts from the perspective of meaning-making and translation of meanings, the graphic means being represented by photographs, logical pictures (graphics, diagrams, etc.), color orientation systems, and font design. These authors draw attention to the relationship between language and image as different sign systems and construct "visual grammar" (in which text is replaced with image) as a tool of effective communication of a large amount of information to the user in the virtual environment. Kress and Van Leeuwen describe patterns of visual structures representing the surrounding world, placing emphasis on the perception of various elements as a single image and on the relationship between the comprehended and the perceived. They based their research on works of philosophers (Goodman, 1969; Hermeren 1969), semioticians (Eco, 1976; Barthes, 1977), art critics (Panofsky, 1970), and media analysts (Williamson, 1978) [Kress, G \& T. Van Leeuwen, 2006, 47].

Yassine considers the multimodality of design products as new communicative artefacts produced as the result of the development of computer technologies and virtual information environment and in response to the changing social and semiotic landscape. In design, the basic role in the ensemble of modes of meaning communication is given to visual elements, whereby the visuals carry considerable communicative load at the cognitive, cultural and ideological levels [Yassine, 2014, 336].

Noteworthy also is the methodology of semiotic modeling of the design product image as a "narrative cocoon" suggested by G. N. Lola, whose theoretical foundation is social semiotics of neo-pragmatic orientation (Bart, Bakhtin, Gasparov, Kazarinova, Eco and others), directed at identifying semiotic resources that could create conditions for meaning-making [Lola, $2011,56]$.

The multimodality of design in this approach does not unfold "horizontally" following the "classical" definition of multiplicity of methods of message 
communication, the most widespread variant being "text" + "image"; rather, it expands "vertically": simultaneously "in depth" of the design product and "outside" towards the socio-cultural context. Design is proclaimed to be a practice of outlining boundaries in meaning-making.

The image of a design product is understood as an essentially unfinished, evolving structure consisting of an image/semiotic model, image/discursive model and message. In the semiotic model, image appears as a holistic meaning formation, as a finished whole; in the discursive model, as a meaning formation open to interpretations with the expansion of the disintegrated whole into discourse; in the message, as a process of meaning production and programming of the design product image towards self-adjustment and self-development [Ibidem, 43].

When discussing the multimodality of virtual information environment design, mention should made of "multimodal interaction", in which the system offers the user several modes of data input and output allowing for temporal and semantic combinations of different modalities. The user can, on the one hand, enter data by means of several "modalities" (besides the keyboard and mouse, these could be speech synthesis, writing input, touch, gesture, glance, head or body movement); on the other hand, obtain information about the system in "multimodal" format (speech synthesis, smart graphics, etc.). An interactive multimodal system combines, as a rule, visual and tactile (monitor, keyboard and mouse) and voice modalities (speech recognition, speech and sound synthesis) [Hoste, Dumas, Signer, 2011].

The complexity of multimodal interaction is that it transforms our vision of temporal and spatial organization: unlike studies devoted to actions developing in a linear and consistent manner, moment by moment (for instance, examination of such interaction with the help of conversation analysis), research focusing on multimodal interaction examines chronological forms combining and interweaving a lot of simultaneously occurring complex forms of interaction [Mondada, 2016, 341]. This creates problems for the analysis of multimodal interaction, including analysis of language, body movements, and verbal, visual and other sensory signals.

\subsection{Multimodal design-texts in socio-cultural context}

Being a cultural phenomenon, the artificially created virtual information environment consists of signs which are perceived with the help of senses and interpreted through the lens of personal human experience. The facilitation of exchange with non-language forms of message during the period 
when the virtual information environment was expanding rapidly catalyzed research into the phenomenon of multimodality. In the second half of the $20^{\text {th }}$ century, the academic language saw the emergence of a large group of notions designed to describe the specifics of increasingly complex media-communication, a semiotic complex operating as an integral whole: transmediality, intermediality, intramediality, multimodality, polycode. hybridity, mixed discourse, creolization, etc. [Kozhemyakin, 2019, 5]. Even the prototypic text ("small text" with representative semiotic space, including letters, encyclopedic entries, interviews, recipes, etc.) is considered today in the virtual information environment to be multimodal rather than of language, which is explained by increasing integration of images as well as systemic text design (Ross, 2001; Seebass, 2001; Stöckl, 2004) [Baakh, 2019, 3].

With reference to virtual information environment design, the notions of multimodality, multicanality or multimediality (where "medium" is commonly understood as image, text, sound) express "the holisticity, simultaneity and continuity of meaning-making with the help of the entire range of modes of its communication" [Zagidullina, 2019, 184].

The property of being holistic is understood as full informative and formal wholeness and completeness of multimodal design texts which cannot be reduced to the sum total of linguistic and non-linguistic modalities as its particularities. The essence of the holistic approach is in the qualitative peculiarity of multimodal design-text as a whole, relationships between the whole and its parts, priority of some parts over the others, and the acquisition by some modalities being parts of the whole of new qualities, regularities and properties which are not inherent in them separately.

The property of being holistic harbors a prerequisite of being creative and of creative productivity: “...given the properties of the parts and the laws of their interaction, it is not a trivial matter to infer the properties of the whole" [Simon, 1996, 184]. A design product considered as a system of multimodal elements may be quite simple: "The apparent complexity of our behavior over time is largely a reflection of the complexity of the environment in which we find ourselves" [Ibidem, 66].

Simultaneity in design is understood as a simultaneous representation of images/modules in the space of a design product's single image, reflecting the designer's views on the state-of-the-art ways of achieving effective design communication based on various techniques of synthesis [Petrov, 2010, 10]. The simultaneity of multimodal design texts implies, on the one hand, a huge 
potential for renewal of the language of design; and, on the other hand, unavoidable subordination of the design process to global social, political and cultural processes.

The simultaneous method of design-object representation is seen in objects completed within the framework of the image to which they belonged initially and assuming the role of interim "modules" in the development of the image of a new object of design [Petrov, 2010,6]. This aspect relates to the domain of multimodality study in its close connection with culture, particularly with cultural standards. In this domain, it is claimed that contemporary human thinking is citational and design is a citational activity founded on mechanisms of imitation, copying, borrowing, interpretation, adaptation, treatment, processing, duplication, combination, author's adaptation, etc.

Simultaneity as the property of objects of design is inexorably associated with the phenomenon of intertextuality, or interconnection of various elements of design and art in a unified multimodal design text within the framework of one culture, "global culture" in particular [Isagulov, 2019, 38]. The intertextuality of multimodal objects of virtual information environment design may be classified as follows:

1. Artistic intertextuality - interaction of artistic codes in the medial diversity of forms. For instance, "musicality", "plasticity", "theatricality" of virtual interactive systems.

2. Normative intertextuality - creation of a design product based on "classical images" where the original object acts as a model or standard. For instance, the use of an "image of a real button" in the design of a button on the display of the computer or some other gadget in a virtual interactive system. As a consequence, what happens is the creation of a "meta-language of design" i. e. a holistic multiple-meaning space in the system of culture.

3. Citational intertextuality - the content of one medium cites the content of another medium acting as a reference source. New artistic images are created in the design product through a dialogue of cultures by means of references. For instance, the use of the composition, colors and plasticity of the Soviet constructivist political poster in the design of an interactive system.

A. N. Lavrentyev noted: "Design is, at the same time, both a product of culture, a tool of cultural construction and a factor actively forming culture" [Lavrentyev, 2007, 7]. Design in the evolving historical and socio-cultural contexts changes standards employed for creation and use of the sign as a communicative resource for the production of meaning. 


\subsection{Design as discourse. The "power" of the designer}

Most of the contemporary researchers studying design multimodality interpret design as discourse. Whereas in the semiotic model the image presents itself as a holistic meaning, in the discursive one it appears as a meaning open for interpretations.

Let us also consider the product of design as discourse. Based on the definition of discourse given by T. A. van Dijk, we understand design discourse as an accomplished or ongoing communicative act, as a complex communicative event and its finalized result designed by the addressor (designer) and interpreted by the addressee (user) in a certain temporal, spatial and cultural context [Van Dijk, 1998].

The multimodal components of design discourse operate allowing for certain socio-cultural factors, as well as personal characteristics of recipients, their needs, emotions and experiences. A multimodal product of design discourse is related to culture, linked to the context, is homogeneous and relevant and belongs to a certain genre. The main goal of design discourse is coordination of activities among people in society. The means to achieving this goal is by changing users' mental states: their knowledge, estimates, values, and volitional impulses. In the "designer-user" discourse, there is implicit inequality in relations: the designer performs the role of an "expert" capable of influencing the user's behavior by virtue of his professional competence. The "power" of the designer also explains the skeptical attitude to graphic design as confined to commercial tasks as V. Papanek stated in his work "Designing for the Real World" [Papanek, 1971]. This power consists in a strong and often unconscious impact on the addressee (user) associated with simple and quick emotional perception of visual information and graphic images and with the possibility to attract attention and imprint the image in the mind.

In design communication through multimodal design texts, the designer can both convey and distort the meaning, inform the user or manipulate them. Note also that "various semiotic resources are used for communicating ideas, values and identities, and these resources can both facilitate the improvement of various types of interaction and hinder them" [Gavrilova, 2016, 107].

The imperative message of design texts correlates with the issue of relations between language and authorities and R. Bart's concept of "myth": design texts directed at changing the reality aim to create a value-based image of the reality while, at the same time, concealing their ideological essence 
and passing manipulative messages for something natural. Thus, the function of design may consist in replacing true human motives with preferable ones.

At the same time, the designer combines units of information into a harmonious whole and directs the sequence of perception: the main and the subordinated, the compositional organization and the visual images helping to communicate the information (presenting, for instance, dry data and charts expressively and figuratively as infographics). The designer helps the user orientate in large amounts of information, "protects" against perceptional overload while directing towards the area prescribed by the customer.

3.4. User experience in the perception of multimodal products of design

Objects of the virtual information environment are sensory experiences, which do not exist outside our perception: “... it may be said that Internet images are not images of the world but the world itself that has become an image" [Aronson, 2004, 153]. The perception of multimodal objects of virtual information environment design is an act of intuitive perception of objects which are not a part of physical information. Such perception cannot be subject to a possible error since it is completely mental [Jackson, 1982].

Interpretation of signs involves issues of comprehension and incomprehension. It would be inaccurate to speculate about the specifics of semiotic representation of information without studying how people interact with the world and react to the world and to their own reactions and those of other people. Today we would be unable to describe a "red color experience" to a person who has never seen red color (from F. Jackson's thought experiment (Mary's Room)). We are of the opinion that a sensory experience is not identical to the description of this experience and, furthermore, description of reality is not reality itself ("The map is not the territory" [Korzybski, 1931]): "Who feels the taste knows it; who doesn't feel it, doesn't know it". The proverb "Seeing something once is better than hearing about it a hundred times" reveals the communicative efficacy of graphic representations.

Analysis of the boundaries of multimodality in design becomes even more complicated when we deal with multimodality manifestations based on empirical knowledge, i. e. the totality of sensory experiences acquired by the individual in the process of interaction with the outside world. This multimodality may be expressed in a relationship between the visual and the 'bodily', when the "visuality" of the world is formed by bodily processes. This type of relationship is described in studies of the body-oriented approach and the concept of "embodied simulation", where the body of the viewer and 
his activity set conditions for the perception of screen-art images [Denikin, 2017, 117].

When the text perceived visually is "heard" through the means of inner speech with simultaneous production of new visual images, we can speak about a relationship between the visual and the auditory. Simultaneous perception of movement, weightlessness, flight and congestion when contemplating dynamic visual and auditory images point to the alliance of the visual, the auditory and the proprioceptive. A sour taste when seeing an image of lemon or hearing the word "lemon" is produced in us by the interaction of the visual, the auditory and the gustatory.

By way of interpreting the postulates of the theory of radical behaviorism with reference to the limits of multimodality in design, we can assume that owing to the mechanism of conditioned reflex, we can "see or hear 'stimuli which are not present"': we can perceive (see, hear or sense) an image not only when shown this image but also when a stimulus is presented which often accompanies the image: "The dinner bell not only makes our mouth water, it makes us see food" [Skinner, 1952].

An individual can mentally construct a visual, auditory or kinesthetic image based on certain stimuli which may have no direct relation to the image presented. This is also true of human emotional reactions caused by stimuli which are present when positive or negative events occur, which determines to a considerable extent attitude to this or that image. Proceeding from the theoretical premises of behavior psychology, we can state that an individual "sees", "hears", "senses" a lot more than the directly presented stimuli actually carry.

We call this manifestation of multimodality "aprioric", whereby a multimodal image is pre-constructed as a whole entity. There are substantial potentialities here for the designer to produce a multimodal impact on the user.

3.5. Intentionality as a prerequisite to perception of multimodal design-text

We understand intentionality, on the one hand, within the mode of desirability, selectivity, interest in the perception of an object of design; on the other hand, as the ability of a design product to reflect the communicative intent of its designer, achievement of the objective pursued (intention of persuasion, motivation, stimulation, information, entertainment, teaching, etc.). In both aspects, intentionality presents two inter-related parts of the designer's single intent: the user's intent acquires continuation in the designer's intent expressed in the design product, i. e. in the discourse created by him/her. 
In design, intentionality may be treated as a phenomenon setting forth a communicative attitude and determining the super-objective of communication. On this basis, the designer forms a strategy of future communication through the design product - a plan of influence on the consumer chosen in accordance with the objective set.

The issue of intentionality as the possibility to have different convictions in relation to one and the same object is linked to the issue of dual contingency (dual dependence) of interaction. On the one hand, the stimulus for communication is the choice made on the basis of the needs of one of the communication participants (a customer); the reaction of the other participant, in turn, will depend on both the stimulus presented and on the needs of the other participant (a user). Assumingly, the perceptions and reactions of the partners in an act of communication are not determined uniquely. In practice, we can see examples of effective interaction both between individuals and between the designer and the user. How does this interaction happen in the context of extreme uncertainty?

Firstly, the designer creates a precedent by ensuring satisfaction of the customer's needs through the satisfaction of the user's needs. This intricate chain of relationships is further complicated by the format of satisfaction of the user's needs through design products, as well as the format of satisfaction of the customer's needs determined in financial terms.

Secondly, because of double contingency (mentioned above), "communication ... could not exist without both generalization from the particularity of the specific situations ... and stability of meaning which can only be assured by "conventions" observed by both parties" [Parsons, 2002, 437]. Moreover, double contingency "implies the normative orientation of action" in a symbolic system shared by all participants of communication [ibidem]. In other words, communicating in the system "customer-designer-user", the participants of communication observe formal and meaningful conventionality of the shared symbolic system acting on preset rules - external symbols generate shared and mutually complementary images. The culture of a certain society sets standards - value-orientations - applied in the evaluation of design products.

Design communication is an essential condition for the production of cultural standards "... as a source for creating meaning and constructing experience. Texts belong to the language system and are determined by the situational context, the semiotic structure of which, in turn, is de- 
termined by the context of culture" [Gavrilova, 2016, 104]. Thus, we can question the difference between the essential foundations of sign typology as icon, index and symbol according to Peirce (the icon is based on likeness; for the index, the factual connection is "real"; and only symbols are conventional). Signs of different modalities have common ultimate conventionality and make up a whole multimodal design-product.

By way of concluding, the user/recipient's empirical knowledge coherent to the semiotic content of a multimodal design-text is an essential precondition to comprehensive perception of the design product. In this regard, it is particularly important to examine the role of generalized symbolic means of communication and cultural values in the design of multimodal texts of design communication.

\section{Results and discussion}

Consideration of the products of virtual information environment design as multimodal texts expands the boundaries of the traditional approaches to the study of design based on the premises of social semiotics and theory of discourse.

The multimodality of virtual information environment design may be discovered in both the design product and the channels and means of design communication. The design product as a complex semiotic object expresses through multimodality the characteristics of the material embodiment of various media and signs - texts, images, animation, etc. The key semiotic form of multimodal products of virtual information environment design is image (photograph, illustration, diagram, chart), combined with other semiotic forms, mainly with text. Considering a design product as multimodal text implies studying the role of generalized symbolic means of communication in the development of design-communication.

Multimodal interaction, in turn, involves the provision of several modalities simultaneously to ensure interaction between the user and the object of virtual information environment design, i. e. a virtual interactive system. Multimodal interaction implies the simultaneity of use of various resources, such as facial expression, posture, gesture, glance, body movements, as well as the use of phonetics, lexis and grammar for organizing interaction between participants in communication.

We understand context in its broad sense as expression of an experience and as any factor — semiotic, cultural, or psychological — influencing 
the interpretation of design-texts. Context may be conventionally divided into external, or situational conditions of communication, and internal, or psychological factors and the entire previous experience of the interacting parties influencing the process of communication. Context enables the semiotic analysis of multimodal design products to be supported by sociological, historical and cultural studies.

Design discourse practice is determined by context and ensures direct experience. Discourse is a phenomenon of broad scope, including social, cultural and historical factors, as well as specific features of a concrete interactive context. Discourse analysis may be directed at the specifics of interaction between the user and the virtual interactive system. Within the framework of design discourse studies, one of the issues is design ethics and the power of the designer contained in the communicative potential and persuasiveness of objects of virtual information environment design.

The multimodal design text which is in the author's mind and the text perceived by the recipient are not identical. Design-text perception and comprehension involve reproduction of personal meanings generated by the user's own experience. The designer's message and the user's perception have an area of overlap, the boundaries of which are determined by the quality of the semiotic design text and by the extent to which the conceptual systems of the designer and the user embodied in conventional signs match up. The time separating the moment the design product is created from the moment of its perception in the virtual information environment is extremely condensed: the environment possesses the property of being continually updated, staying relevant and even "outpacing" time.

Thus, study of design products may be connected, first, with study of holistic, simultaneous multimodal design texts; second, with analysis of external conditions of communication (accessibility, informativity, situationality); third, with consideration of psychological factors underlying the perception of design products and the experiences of interacting participants (intentionality, intertextuality).

\section{Conclusions}

The study has revealed the following manifestations of multimodality in the virtual information environment:

1. "Structural multimodality" - the multimodality of a design product consists of several modes of meaning communication (image, text, animation, etc.). 
2. "Citational multimodality" - manifests itself in the citation of elements and various objects of art existing within the framework of one culture or in different cultures, including "global culture", in a single multimodal design text: multimodality evolving through the intertextuality of culture.

3. "Aprioric multimodality" - multimodal perception expressed in one or several modalities based on the user's previous experience. It involves mental reconstruction of visual, auditory and sensory images based on the stimulus presented. It increases the value of the user's subjective perception and experience and places emphasis on the study of, first and foremost, the pragmatics of the communicative act in design.

It is worth mentioning individually "multimodal interaction" as the property of distinctive objects of virtual information environment design, i.e. interactive systems. Multimodal interaction implies simultaneous presence of several modalities for the interaction between the user and the interactive system to happen.

For effective perception of a multimodal design-text, the imagery of the design product should match the experience of images and the immediate objectives of the perceiving subject. We distinguish the following regularities in the perception of multimodal design products:

1. The higher the compositional, meaningful and stylistic complexity of a multimodal design product, the greater the cognitive activity required from the user for its perception.

2. The higher the perceiving agent's level of preparedness for perception and his psychological, social, cultural and intellectual attitudes, the more active is the process of design product perception. Information received in the previous experience is a prerequisite to active perception.

3. The more goal-directed is the activity of perception of a multimodal design product, the higher the measure of activity such perception.

The determination of the boundaries of multimodality in virtual information environment design is proceeding in several directions: in depth into the semiotic structure of the design product and mental processes of its perception; in breadth across numerous forms of organization of interaction among the participants of communication; and in time regarding aspects of cultural citation.

\section{Conflict of Interest}

The authors have no conflict of interest to declare. 


\section{Acknowledgment}

The work was supported by Act 211 Government of the Russian Federation, contract № 02.A03.21.0006.

\section{References:}

1. E. A. Lavrent'eva. Tekst i kontekst $\mathrm{v}$ graficheskom dizajne: aktual'nye problemy i tendencii vizualizacii teksta [Text and context in graphic design: actual problems and trends in text visualization]. Avtoreferat dis... kandidata iskusstv. Mosk. gos. hudozh.-prom. un-t im. S. G. Stroganova [dissertation abstract... candidate of philological sciences... candidate of arts. Moscow state University of art and industry]. Moscow (2008).

2. G. Kress \& T. Van Leeuwen. Reading Images: The Grammar of Visual Design. Routledge, London (2006).

3. S. Yassine. Multimodal Design of EFL Textbooks: A Social Semiotic Multimodal Approach. Anglisticum Journal. Vol. 02(12) (2014), pp. 335-341.

4. G. N. Lola. Dizajn-kod: kul'tura kreativa [Design code: culture of creativity]. Elmor, Saint Petersburg (2011).

5. L. Hoste, B. Dumas, B. Signer. Mudra: A Unified Multimodal Interaction Framework. Proceedings of ICMI 2011, 13th International Conference on Multimodal Interaction. Alicante Spain (2011). www.academia.edu/808762/Mudra_A_ Unified_Multimodal_Interaction_Framework

6. E. A. Kozhemyakin. K Voprosu o metodologii analiza mul'timodal'nyh tekstov. Teksty novogo veka. Materialy Mezhregional'nogo kruglogo stola. [On the methodology of analysis of multimodal texts. Texts of the new century. Materials of the interregional capital round table] (2019), pp. 5-7.

7. Yu. V. Baah. Vizual'naya kommunikaciya i ee svyaz' s yazykom [Visual communications and communication with language]. Elektronnyj nauchno-metodicheskij zhurnal Omskogo GAU [Electronic scientific and methodological journal of Omsk Sate University]. № 3 (18) (2019).

8. M. V. Zagidullina. Mul'timodal'nost': k voprosu o terminologicheskoj opredelennosti [Multimodality: on the issue of terminological certainty] Znak: problemnoe pole mediaobrazovaniya[Znak: the problematic pole of media education.]. № 1 (31) (2019). pp. 181-188.

9. A. Simon Herbert. The Sciences of the Artificial. Cambridge, MIT Press, Massachusetts: (1969).

10. M. A. Petrov. Simul'tannost' v iskusstve. Kul'turnye smysly i paradoksy [Simultaneity in art. Cultural meanings and paradoxes]. Indrik, Moscow (2010). 
11. N. V. Isagulov. Intermedial'nost' kak zontichnyj termin: popytka klassifikacii [Intermediality as an umbrella term: an attempt to classify]. Kul'tura slova [Word culture] № 1 (2) (2019), pp. 28-39.

12. A. N. Lavrent'ev. Istoriya dizajna: uchebnoe posobie [Design history: a textbook]. Gardariki, Moscow (2007).

13. M. V. Gavrilova. Social'naya semiotika: teoreticheskie osnovaniya i principy analiza mul'timodal'nyh tekstov [Social semiotics: theoretical foundations and principles of analysis of multimodal texts]. Politicheskaya nauka [Political studies]. № 3 (2002), pp. 101-117.

14. O. V. Aronson. Obrazy informacii. Vliyanie Interneta na soznanie i strukturu znaniya [Images of information. The influence of the Internet on consciousness and the structure of knowledge]. IF RAN, Moscow (2004), pp. 131-161.

15. A. A. Denikin. Telesno-orientirovannyj podhod pri analize proizvedenij ekrannogo iskusstva [Body-oriented approach in the analysis of works of screen art]. Znanie. Ponimanie. Umenie [Knowledge. Understanding. Skill]. № 2 (2017), pp. 115-131.

16. T. Parsons. O strukture social'nogo dejstviya [About the structure of social action]. Akademicheskij Proekt, Moscow (2002).

17. T. Parsons. Toward a general theory of social action. Routledge; Abridged Edition (January 31, 2001).

DOI 10.15826/B978-5-7996-3081-2.25

\section{Use of New Nature Texts in the VKontakte Social Network}

\section{Gudova Margarita', Glazkova Daria²}

${ }^{1}$ Ural Federal University, Ekaterinburg, Russia

${ }^{2}$ Ural Federal University, Ekaterinburg, Russia

Corresponding author: Glazkova Daria, dio.di.2d@gmail.com

Abstract. Multi-modal or multi-code texts are an important part of modern communicative culture. Frequently, specific feature of this culture could be determined through the creation and usage of such texts. As T. G. Galaktionova, we prefer calling such texts as "new nature" texts and consider their features and 